\title{
Expressão gênica de APAF-1 em CMSP de indivíduos portadores de periodontite
} crônica.

\author{
Caroline Patricio Maia ${ }^{1}$; Soraya Castro Trindade ${ }^{2}$; Paulo Cirino de Carvalho Filho ${ }^{3}$; \\ Marcia Tosta Xavier ${ }^{4}$; Isaac Suzart Gomes Filho ${ }^{5}$, Roberto José Meyer Nascimento ${ }^{6}$ \\ 1. Bolsista PROBIC/UEFS, Graduando em Odontologia, Universidade Estadual de Feira de Santana, e-mail: \\ caroline.maiia@hotmail.com \\ 2. Orientadora, Departamento de Saúde, Universidade Estadual de Feira de Santana, e-mail: soraya@uefs.br \\ 3. Participante do projeto, Departamento de Saúde, Universidade Federal da Bahia, e-mail: pauloccf@ yahoo.com \\ 4. Participante do projeto, Departamento de Saúde, Universidade Federal da Bahia, e-mail: tostamarcia@ gmail.com \\ 5. Participante do projeto, Departamento de Saúde, Universidade Estadual de Feira de Santana, email: isuzart@gmail.com \\ 6. Participante do projeto, Departamento de Saúde, Universidade Federal da Bahia, email: \\ rmeyer@ufba.br
}

PALAVRAS-CHAVE: Periodontite crônica; APAF-1; Porphyromonas gingivalis.

\section{INTRODUÇ̃̃O}

Porphyromonas gingivalis é um dos mais importantes agentes etiológicos associados com a periodontite, uma doença inflamatória de etiologia multifatorial, geradora de condições inflamatórias, que resultam na destruição dos tecidos de sustentação dos dentes (TRINDADE et al., 2012; TRINDADE et al., 2013).

A resposta do hospedeiro contra a infecção periodontal inclui o recrutamento e ativação de células do hospedeiro, como monócitos/macrófagos, linfócitos, fibroblastos e outros tipos celulares, induzindo o desequilíbrio na produção de mediadores inflamatórios e suas moléculas contra-regulatórias (DEZEREGA et al., 2010).

Componentes de Porphyromonas gingivalis modulam a resposta imune do hospedeiro por meio de indução de apoptose de linfócitos $\mathrm{T}$ e macrófagos. Dentre os principais determinantes antigênicos indutores de apoptose desta bactéria, destaca-se 0 lipopolissacarídeo (LPS) (TRINDADE et al., 2012), uma molécula presente na membrana externa do patógeno, e HmuY, uma proteína de membrana com a função de captar ferro no microambiente para a nutrição bacteriana (OLCZAK et al., 2010).

No processo de morte celular programada, a proteína HmuY induz altos níveis de Bcl2, resultando na apoptose tardia em células mononucleares do sangue periférico (CMSP) e necrose celular, prolongando o processo de destruição tecidual (TRINDADE et al., 2012; CARVALHO-FILHO et al., 2013). Um dos mecanismos utilizados pelas mitocôndrias para induzir a morte celular é a liberação de proteínas pró-apoptóticas no citosol. O citocromo c, a primeira molécula que se mostra ser liberada, se une com o fator 1 de ativação da protease da apoptose (APAF-1) e expõe os domínios de Apaf-1 que ativam a caspase-9. Uma cascata proteolítica que eventualmente se segue e ativa as caspases efetoras $-3,-6$ e -7 . (URNOWEY et al., 2006)

Diante da possibilidade de alterações na apoptose por bactérias presentes no biofilme subgengival e, consequentemente, na patogênese da periodontite, o presente trabalho se propõe a avaliar a expressão gênica de APAF-1 em indivíduos com e sem periodontite crônica.

\section{MATERIAL E MÉTODOS}

Foi realizado um estudo experimental com pessoas com idades acima de 18 anos e de ambos os sexos, que buscaram voluntariamente os ambulatórios do curso de Odontologia da Universidade Estadual de Feira de Santana. 
Os critérios de exclusão avaliados pela anamnese e considerados para este estudo foram: diabetes, hipertensão, doenças auto-imunes, doenças reumáticas, gestação atual, tratamento periodontal anterior, tabagismo atual ou anterior, uso de antibióticos e antiinflamatórios, respectivamente, nos três e um meses anteriores à coleta.

Os indivíduos foram examinados quanto descritores clínicos periodontais para o diagnóstico da periodontite (GOMES FILHO et al. 2007).

Em seguida, foram coletados $20 \mathrm{~mL}$ de sangue, por punção venosa na fossa antecubital com tubo à vácuo estéril (BD-SP) com heparina e as CMSP foram obtidas por gradiente de densidade (TRINDADE et al., 2012a,b). As CMSP foram cultivadas em placas de 24 poços po $48 \mathrm{~h}$ a $37^{\circ}$, em estufa de $\mathrm{CO} 2$, sob o estímulo da proteína recombinante $\mathrm{HmuY}$ de Porphyromonas gingivalis. O mitógeno Pokweed foi usado como controle positivo e um poço sem estímulo foi utilizado como controle negativo.

Depois da extração de RNA das CMSP, as amostras foram analisadas por meio da técnica de microarray. Para isso um Oligo GEArray® customizado e focado (número de referência COH-0049, SuperArray BioscienceCorporation, Frederick, MD) foi especialmente desenvolvido para essa pesquisa. Foram selecionados 288 genes relacionados à apoptose, resposta de células $\mathrm{T}$, inflamação e receptores de citocinas. As sondas foram selecionados a partir da terminação $3^{\prime}$ dos transcritos com base me critérios tais como, guanina-citosina (GC) e temperatura de fusão (Tm).

As sequências de 60 pares de base foram então submetidas a um BLAST (basic local alignment search tool- http://www.ncbi.nlm.nih.gov/BLAST/) para comparação com todos os transcritos conhecidos e disponíveis no GenBank, evitando-se assim sequiências com reatividade cruzada. Essas sondas de 60 pares de base foram então sintetizadas (Qiagen® Valencia, CA, http://www1.qiagen.com) para a realização da PCR.

A análise dos dados foi feita inicialmente realizando-se uma análise descritiva dos dados relativos a gênero, idade e descritores clínicos foi efetuada, visando a caracterização da amostra. Em seguida, o teste de Mann-Whitney foi empregado para a comparação dos dados entre os grupos.

\section{RESULTADOS E/OU DISCUSSÃO}

Participaram do presente estudo 16 indivíduos, oito com periodontite crônica grave (Grupo PC) e oito sem periodontite (Grupo SP). A média ( \pm desvio padrão) da idade dos participantes do grupo PC foi de $43.88 \pm 13,9$ anos e do grupo SP foi de $36.63 \pm 10.8$ anos. Cada grupo foi composto de dois homens e seis mulheres. Não houve diferença estatisticamente significante na média da idade $(\mathrm{p}=0,22)$, na proporção de indivíduos do sexo masculino e feminino $(p=1,00)$ e na quantidade de dentes presentes na boca $(p=0,98)$ entre os dois grupos, demonstrando que ambos foram homogêneos no que diz respeito a estas covariáveis (Tabela 1). Em contrapartida, como esperado, houve diferença nos descritores clínicos periodontais, como pode ser observado na tabela 1.

Tabela 1: Achados clínicos dos grupos sem periodontite (SP) e com periodontite crônica grave (PC).

\begin{tabular}{llll}
\hline & SP & PC & P \\
\hline Número de homens/mulheres & $2 / 6$ & $2 / 6$ & 1.000 \\
Idade (anos) (média \pm DP) & 36.63 & $43.88 \pm 13,9$ & 0.223 \\
& \pm 10.8 & & \\
Número de dentes (média \pm & 20.13 & $20.31 \pm 6.5$ & 0.983 \\
DP) & \pm 6.2 & & \\
$\%$ SS (média \pm DP) & 8.78 & 46.23 & 0.001 \\
& \pm 11.49 & \pm 14.43 & \\
$\%$ PS $\geq 4$ (média \pm DP) & 1.01 & 16.33 & 0.000 \\
& \pm 1.55 & \pm 11.44 &
\end{tabular}




\begin{tabular}{llll}
$\%$ NIC $\geq 3($ média \pm DP) & 20.40 & 61.87 & 0.001 \\
& \pm 14.03 & \pm 17.34 & \\
$\%$ NIC $\geq 5$ (média \pm DP) & $0.45 \pm 1.2$ & $23.26 \pm 16.7$ & 0.000 \\
& 7 & 2 & \\
\hline
\end{tabular}

DP Desvio Padrão, SS Sangramento a Sondagem, PS Profundidade de Sondagem, NIC Nível de Inserção Clínica.

Os resultados da expressão gênica por CMSP nos grupos de pacientes com periodontite crônica foram dados pelo nível de expressão gênica relativa, onde os genes avaliados apresentaram-se "upregulated" ou "downregulated" quando comparados com os transcritos obtidos das CMSP de pacientes sem periodontite crônica. Foram considerados os genes que apresentaram expressão com nível de significância $p \leq 0,05$. Os resultados foram apresentados através do mapa de calor (Figura 1), e gráfico em caixa (Figura 2).

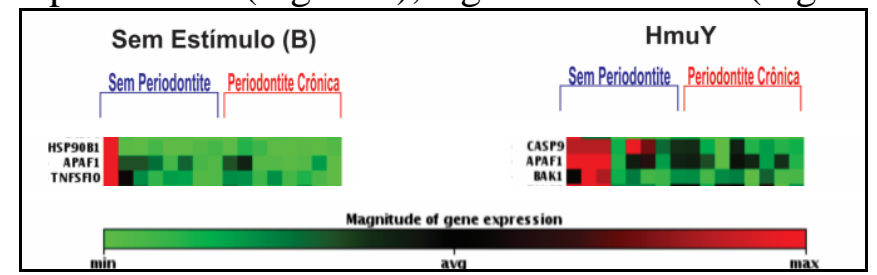

Figura 1 - Identificação da expressão gênica de APAF-1 por CMSP de indivíduos com periodontite crônica (PC) e sem (SP) sob estímulo de rHmuY de Porphyromonas gingivalis e na ausência de estímulos. O gradiente de cor verde-preto-vermelho representa níveis relativos de expressão gênica, indicando "Under-Even-Over" regulação, respectivamente.

Foram observados a sub-regulação (downregulated) e menores níveis de expressão gênica relativa para APAF1 por CMSP de indivíduos do grupo PC em comparação com os níveis produzidos por células de indivíduos do grupo SP, quando as células foram cultivadas sob estímulo de rHmuY ( $\mathrm{p}=0,0478$ ) (Figura 2).

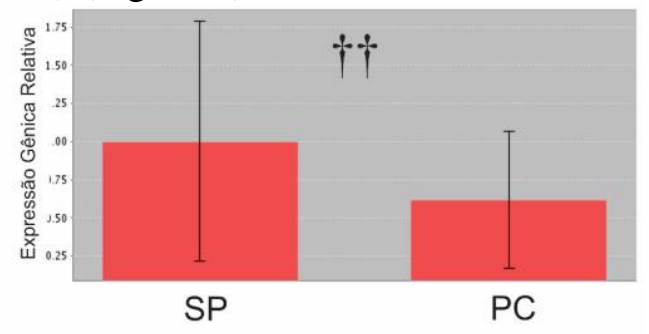

DAPAF

Figura 2 - Expressão relativa de mRNA para APAF1 em cultura de CMSP de indivíduos com periodontite crônica (PC) e sem a doença (SP), sob estimulo de rHmuY de Porphyromonas gingivalis (HmuY). $\dagger \dagger \mathrm{p}=0,0478$

Estudos anteriores revelaram o potencial imunogênico de HmuY de Porphyromonas gingivalis por demonstrar o seu papel no processo inflamatório, induzindo altos níveis de Interleucina-1 beta (IL-1 $\beta$ ) e interleucina-10 (IL-10) em CMSP de indivíduos com periodontite crônica (TRINDADE, 2012a), além de participar e interferir em mecanismos de morte celular (TRINDADE, 2012b; CARVALHO-FILHO, 2013).

Os achados do presente estudo indicam diferenças na expressão de mRNA de APAF1 por CMSP dos grupos SP e PC sob estímulo de rHmuY. APAF1 é uma molécula que participa da sinalização molecular de apoptose na via intrínseca. Poucos trabalhos na literatura atual têm demonstrado a participação da via intrínseca da apoptose na periodontite. A maioria dos estudos sobre esta via na doença periodontal incluem moléculas anti-apoptóticas, como BCL-2, BCL-X e BCL-6 (WANG, 2015; LAKSCHEVITZ, 2013; CARVALHO-FILHO, 2013).

Estímulos apoptóticos intrínsecos, tais como danos ao DNA ou estímulos estressores ao retículo endoplasmático, podem ativar proteínas $\mathrm{BH} 3$ que levam à ativação de $\mathrm{BAX}$ e 
BAK e por consequência, à permeabilização da membrana mitocondrial externa (PMME). A proteína anti-apoptótica BCL-2 evita a PMME pela ligação com proteínas BH3 e com BAX ou BAK ativadas. Após a PMME, ocorre a liberação de várias proteínas do espaço intermembranar mitocondrial (EIM), promovendo a ativação de caspases e apoptose. $\mathrm{O}$ citocromo c liga-se à APAF1, induzindo a sua oligomerização e formando assim uma estrutura denominada apoptossomo que recruta e ativa um iniciador de caspase, a caspase 9, que por sua vez, cliva e ativa caspases executoras, caspase 3 e caspase 7, levando à apoptose. (STEPHEN, 2010).

\section{CONCLUSÃO}

HmuY de $P$. gingivalis reduziu os níveis de expressão de APAF1, gene envolvido na via intrínseca de apoptose, por CMSP de indivíduos do grupo PC, sugerindo também o papel de HmuY em impedir a ativação da cadeia sinalizadora desta via à nível trascripcional em pacientes com periodontite crônica.

\section{REFERENCIAS}

ASHIMOTO, A. et al. Polymerase chain reaction detection of 8 putative periodontal pathogens in subgingival plaque of gingivitis and advanced periodontitis lesions. Oral Microbiol Immunol. v. 11, p.266-273, 1996.

CARVALHO-FILHO et al. Porphyromonas gingivalis HmuY stimulates expression- of Bcl-2 and Fas by human CD3+ T cells. BMC Microbiology, vol. 13, n. 206, 2013.

DEZEREGA, A.; POZO, P.; HERNANDEZ, M.; OYARZU`N, A.; RIVERA, O.; DUTZAN, N.; GUTIÉRREZ-FERNA NDEZ, A.; OVERALL, C.M.; GARRIDO, M.; ALCOTA, M.; ORTIZ, E.; GAMONAL, J. Chemokine monocyte chemoattractant protein-3 in progressive periodontal lesions in patients with chronic periodontitis J Periodontol. v.81, p.267-276, 2010.

LAKSCHEVITZ, F.S.; ABOODI, G.M.; GLOGAUER, M. Oral neutrophil transcriptome changes result in a pro-survival phenotype in periodontal diseases. PLoS One. v.8, p.e68983, 2013.

TRINDADE, S.C., et al. Induction of interleukin (IL)-1 $\beta$, IL-10, IL-8 and immunoglobulin G by Porphyromonas gingivalis HmuY in humans. J Periodontal Res. v.47, p.27-32, 2012a.

TRINDADE, S.C., et al., Porphyromonas gingivalis antigens differently participate in the proliferation and cell death of human PBMC. Archieves of oral biology, 57: 314-320, 2012b.

WANG, Q.; SZTUKOWSKA, M.; OJO, A.; SCOTT, D.A.; WANG, H.; LAMONT, R.J. FOXO responses to Porphyromonas gingivalis in epithelial cells. Cell Microbiol. v.12459, 2015. 